\title{
The Conversion of Alantolactone into Dihydroeudesmol
}

The configuration of $\mathrm{A} / \mathrm{B}$ ring juncture is the first one to be settled for the stereochemistry of alantolactones (naturally occurring alantolactone, isoalantolactone, and dihydroisoalantolactone). In the present communication, I wish to report on the conversion of alantolactone to dihydroeudesmol.

The glycol (II) obtained by the action of lithium aluminum hydride on tetrahydroalantolactone (I) was dehydrated to a $\beta, \gamma$-unsaturated alcohol (III), which was catalytically hydrogenated and subsequently oxidized to 4,9-dimethyl-6-(2'-carboxyethyl)decalin $\left(\mathrm{V}\right.$; the amide, m.p. $139 \sim 140^{\circ},[\alpha]_{\mathrm{D}}+35.7^{\circ}$. Anal. Calcd. for $\mathrm{C}_{15} \mathrm{H}_{27} \mathrm{ON}: \mathrm{C}$, $75.89 ; \mathrm{H}, 11.47 ; \mathrm{N}, 5.90$. Found : C, 75.86; H, 11.49; N, 5.94). The methyl ester of $(\mathrm{V})$ was treated with phenylmagnesium bromide to afford a mixture of the corresponding tertiary alcohol (VI), m.p. $140 \sim 141^{\circ}$ (Anal. Calcd. for $\mathrm{C}_{27} \mathrm{H}_{38} \mathrm{O}: \mathrm{C}, 86.11 ; \mathrm{H}, 9.64$. Found: C, 85.62; H, 9.59) and its dehydrated product (VII), m.p. 109 110 (Anal. Calcd. for $\mathrm{C}_{27} \mathrm{H}_{34}$ : C, 90.44; $\mathrm{H}, 9.56$. Found : $\left.\mathrm{C}, 90.88 ; \mathrm{H}, 9.47\right)$; the former being easily dehydrated to the latter on refluxing with $p$-toluenesulfonic acid in benzene. (VII) was subjected to the ozonolysis to give 4,9-dimethyl-6-acetyldecalin (VII ; the semicarbazone, m.p. 206 208 . Anal. Calcd. for $\mathrm{C}_{15} \mathrm{H}_{27} \mathrm{ON}_{3}:$ C, 67.88; H, 10.26; N, 15.83. Found: C, $68.00 ; \mathrm{H}, 10.10 ; \mathrm{N}, 16.00)$, which, on treatment with methylmagnesium iodide, gave

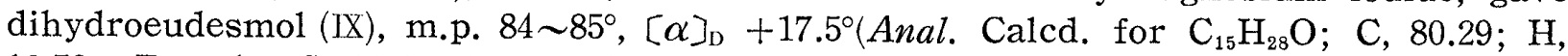
12.58. Found : $\mathrm{C}, 80.10 ; \mathrm{H}, 12.26)$. The synthesized dihydroeudesmol was identified by mixed melting point and by the comparison of their infrared spectra with the authentic specimen, for which I wish to express my appreciation to Prof. S. Shibata.

Eudesmol has been reported by Riniker, et al. ${ }^{1}$ to have a trans-decalin structure<smiles>CC(=O)OC1CC2CCCCC2CC1C</smiles>

( I )

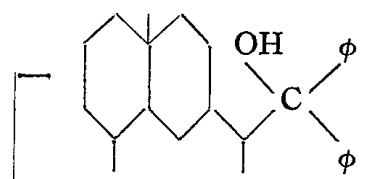

(VI)

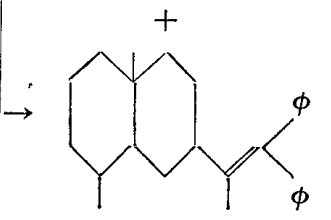

(VII)<smiles>CC(C)C1CC(C(C)CO)C2CCCC1(C)CC2O</smiles>

(II)

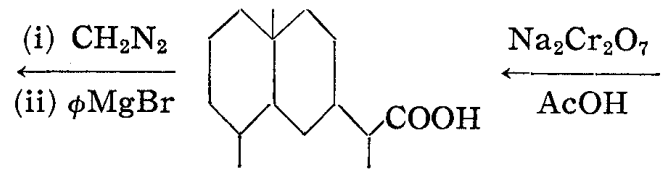

(V)

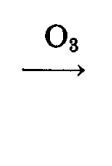<smiles></smiles>

$\mathrm{CH}_{3} \mathrm{MgI}$

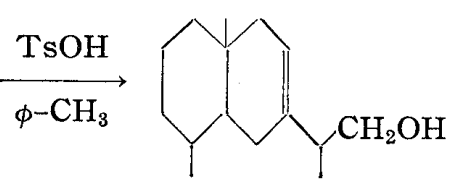

(III)

$\downarrow \mathrm{Pt}-\mathrm{AcOH}$

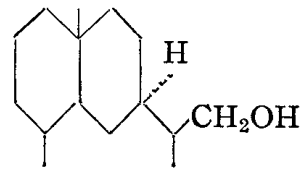

(IV)

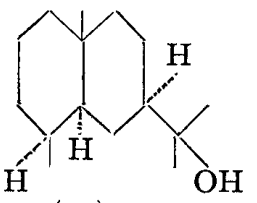

(IX)

1) B. Riniker, J. Kalvoda, D. Arigoni, A. Fürst, O. Jeger, A.M. Gold, R. B. Woodward : J. Am. Chem. Soc., 76, 313(1954). 
in correlation with the steroid, and, thus, alantolactones have not only the same transfused $A / B$ ring but must also be represented as (I) and not by its mirror images.

Takamine Research Laboratory

Sankyo Co., Ltd.

Katsumi Tanabe (田辺克巳)

Nishi-shinagawa

Shinagawa-ku, Tokyo

October 28, 1957

UDC 547.837

\section{Dipole Moments of Matridine and Allomatridine}

One of the present writers ${ }^{1)}$ has succeeded in the total synthesis of allomatridine and proposed to assign the structure (I) to allomatridine and (II) to matridine on the basis of qualitative conformational analyses.<smiles>CC12CCCCN1CC1CCCN3CCCCC12C3</smiles>

(I)<smiles>CC12CCCCN1CC1CCCN3CCCCC132</smiles>

(II)

It is apparent that further investigation of these compounds using physical technique is essential before one can decide between various possible conformations for these compounds with any confidence. With this object in view, the dipole moment of these compounds was measured in benzene solutions at $25^{\circ}$ and the observed values for matridine and allomatridine were $0.63 \mathrm{D}$ and $1.27 \mathrm{D}$, respectively.

The dipole moment data are particularly suitable in this case as a criterion for making the choice among various possible conformations, because the molecule of matridine as well as of allomatridine has only two group moments of the same magnitude located fairly apart from each other. In addition, the angle between the two group moments can easily be evaluated, because the atoms composing the condensed ring can be accommodated in the diamond lattice, provided that the valency angle of nitrogen is assumed to be equal to that of carbon and that all the six-membered rings take a chair form. There are good reasons for believing that the two rings on the lower left side of (I) and (II) are trans-fused. ${ }^{1)}$ With this restriction in mind, one can conceive the conformations (III) and (IV) as possible in addition to the structures (I) and (II) mentioned above.<smiles>CC1(C)N2CCCCC13C(CCC2)CN1CCCCC13C</smiles>

(III)<smiles>CC12CCCN3CCCCC31C1(C)CCCCN1C2</smiles>

(iv)

The two group moments are parallel to each other in the structure (I), while they make a tetrahedral angle $\alpha$ with each other in the structures (II), (III), and (IV), leading

1) K. Tsuda, H. Mishima : This Bulletin, 5, 285(1957). 